(RESEARCH ARTICLE)

\title{
A cross-sectional study on assessment of physical activity level and anthropometric indicators of health risk among students of sixth year of Faculty of Medicine of Sarajevo University.
}

\author{
Amra Catovic* and Amina Halilovic \\ Faculty of Medicine, University of Sarajevo, Sarajevo, Bosnia and Herzegovina.
}

Publication history: Received on 30 September 2020; revised on 08 October 2020; accepted on 12 October 2020

Article DOI: https://doi.org/10.30574/wjarr.2020.8.1.0366

\begin{abstract}
Overweight and obesity are major public health issues worldwide. There is increased risk of obesity-related morbidity due to accumulation of abdominal fat. Regulation of body weight depends on physical activity and diet. Young adulthood is very critical period due to a tendency to gain weight and adopt poor dietary and exercise habits. This study aimed to investigate the relationships of the anthropometrical parameters with physical activity domains in everyday life and sedentary behavior among students of sixth year of the Faculty of Medicine of Sarajevo University. A cross-sectional study was conducted during May 2020. The survey covered 56 students, aged 24, who responded online to questionnaire. A self-administered questionnaire composed of two blocks of questions. In the first block of the questionnaire, questions were related to sex, and anthropometric measures. The second block referred to the practice of physical activity (vigorous, moderate, and walking), and sitting during seven days. The data collected were processed by the descriptive statistical procedure. Overweight and obesity was found at 11(19.65\%). In sample 46.43\% performed vigorous intensity activities that meet with WHO criteria, 58.93 performed moderate intensity activities that meet with WHO criteria, and $39.29 \%$ performed walking activities that meet with WHO criteria. There were positive, statistically significant difference between indicators of abdominal obesity and the average time spent during 7 days in vigorous physical activity. Health and physical educators can utilize these findings to better understand that physical activity, trying to balance diet and activities.
\end{abstract}

Keywords: Anthropometric measurements; Abdominal obesity; Weight Gain; Sedentary lifestyle

\section{Introduction}

Overweight and obesity are conditions in which excess body fat has accumulated to an extent that may impair health. Common health consequences of overweight and obesity are noncommunicable diseases such as: cardiovascular diseases; diabetes; musculoskeletal disorders; some cancers [1].

The prevalence of overweight and obesity has increased dramatically over past four decades. According to WHO statistics 39\% of adults aged 18 years and over were overweight in 2016, and 13\% were obese [2]. Once overweight and obesity were a high-income country problem. Now they have been on the rise in low-and middle-income countries. Intercountry comparable overweight and obesity estimation from 2008 emphasizes problem in Bosnia and Herzegovina: $60.7 \%$ of the adult population ( $>20$ years old) were overweight and $26.5 \%$ were obese [3].

Diagnostic criteria for obesity include several anthropometric parameters: body mass index (BMI), waist circumference (WC), waist-to-hip ratio (WHR), and waist-to-height ratio (WHtR). The BMI is defined as a person's weight (in kilograms) divided by the square of person's height (in meters). It is a crude measure of overall adiposity. Those with a

\footnotetext{
${ }^{*}$ Corresponding author: Amra Catovic

Faculty of Medicine, University of Sarajevo, Sarajevo, Bosnia and Herzegovina.
} 
BMI greater than or equal to 25 are considered being overweight, and those with a BMI greater than or equal to 30 are considered being obese. The WHO STEPS protocol for measuring WC instructs that WC should be measured at the midpoint between the lower margin of the least palpable rib and the top of the iliac crest, using a stretch-resistant tape that provides a constant $100 \mathrm{~g}$ tension. Hip circumference should be measured around the widest portion of the buttocks, with the tape parallel to the floor. WHR (i.e. the waist circumference divided by the hip circumference) is a measure of body fat distribution. It provides an index of both subcutaneous and intraabdominal adipose tissue [4,5]. Waist-to-height ratio is defined as a person's waist circumference divided by person's height. It is a measure of centralized obesity [6].

There is increased risk of obesity-related morbidity due to accumulation of abdominal fat. Abdominal obesity is defined as: a BMI above 30.00 (Table 1) or a WC of $>94 \mathrm{~cm}$ in men and $>80 \mathrm{~cm}$ in women and a WHR above 0.90 for males and above 0.85 for females (determined for European men and women, respectively) (Table 2).

WHtR is the best predictor of cardiovascular risk in both men and women. For people under 40 a cutoff level is 0.5 . Boundary value for men is 0.54 , and for women is 0.49 . The cutoff levels lie between 0.5 and 0.6 for people aged $40-50$, and for people over 50 the critical values start at 0.6 [6].

Table 1 Classification of adults according to BMI [5]

\begin{tabular}{|l|l|l|}
\hline Classification & BMI $\mathbf{( k g} / \mathbf{m}^{\mathbf{2}} \mathbf{)}$ & Risk of comorbidities \\
\hline Underweight & $\leq 18.5$ & Low (but risk of other clinical problems increased) \\
\hline Normal & $18.5-24.9$ & Average \\
\hline Overweight & $25-29.9$ & Increased \\
\hline Obese class I & $30-34.9$ & Moderate \\
\hline Obese class II & $35-39.9$ & Severe \\
\hline Obese class III & $\geq 40$ & Very severe \\
\hline
\end{tabular}

Table 2 Cut-off points of waist circumference and WHR and risk of metabolic complication [4]

\begin{tabular}{|l|l|l|}
\hline Indicator & Cut-off points & Risk of metabolic complications \\
\hline Waist circumference & $>94 \mathrm{~cm}(\mathrm{M}) ;>80 \mathrm{~cm}(\mathrm{~W})$ & Increased \\
\hline Waist circumference & $>102 \mathrm{~cm}(\mathrm{M}) ;>88 \mathrm{~cm}(\mathrm{~W})$ & Substantially increased \\
\hline Waist-hip ratio & $\geq 0.90 \mathrm{~cm}(\mathrm{M}) ; \geq 0.85 \mathrm{~cm}(\mathrm{~W})$ & Substantially increased \\
\hline \multicolumn{2}{|c|}{$\mathrm{M}$, men; $\mathrm{W}$, women }
\end{tabular}

Regulation of body weight depends on physical activity and food consumption patterns. By WHO physical activity is defined as any bodily movement produced by the contraction of skeletal muscles that requires energy expenditure. Physical activity generally refers to the subset of physical activity that enhances health $[7,8]$. There are several activity domains in everyday life. Occupational work activities are undertaken during the course of work. Transportation physical activities are undertaken during traveling from place to place, including to places like work, stores, movies, and so on. Household and other chores activities are undertaken around home, like housework, gardening, yard work, general maintenance work, and caring for family. Leisure-time physical activities are undertaken in the individual's discretionary free time, like recreation, exercise or sport [5,9]. All forms of physical activity can provide health benefits if undertaken regularly and of sufficient duration and intensity [10].

The level of PA intensity depends on the magnitude of the effort required to perform an activity. Moderate PA produces a moderate increase in respiration rate, heart rate and sweating for at least 10 min duration. On an absolute scale, moderate intensity refers to the PA that is performed at 3.0-5.9 times the intensity of rest. Vigorous physical activities are defined as those producing increases in respiration rate, heart rate and sweating for at least 10 min duration and vigorous intensity refers to PA that is performed at 6.0 or more times the intensity of rest for adults $[9,10]$.

Physical inactivity, or sedentary behavior, can be defined as any waking behavior characterized by a low level of energy expenditure while sitting, reclining, or lying (television viewing time, working at a computer, talking with friends on 
the telephone, driving a car, meditating or eating) $[5,8,11]$. A primary cause of most chronic diseases is physical inactivity [12].

There are erosions in PA patterns through adolescents' age, mostly from ages 15 to 18, and during young adulthood (18-29 year). Early development in childhood of overweight leads to obesity in adulthood. Nevertheless the transition between adolescence and young adulthood is a period of increased risk of development of obesity. As longitudinal studies have shown, a substantial amount of weight is gained during the transition from adolescence to young adulthood. This trend is present in both males and females $[13,14]$.

PA patterns of general population, as well as of young adults, have been limited explored in Bosnia and Herzegovina. Exploring this health-related factor is necessary to implement a health promotion program. This study aimed to investigate the relationships of the anthropometrical parameters with physical activity domains in everyday life and sedentary behavior among students of sixth year of the Faculty of Medicine of Sarajevo University.

\section{Methods}

\subsection{Design and Sample}

A cross-sectional study was conducted during May 2020 at Faculty of Medicine of Sarajevo University. The survey covered 56 students from the sixth year of study, aged 24, who responded online to questionnaire.

The study was performed according to the research ethics guidelines laid down in the Declaration of Helsinki [15].

\subsection{Data Collection}

For the collection of data was applied a self-administered questionnaire composed of two blocks of questions. In the first block of the questionnaire, questions were related to sex, and anthropometric measures (height, weight, waist and hip circumference). The second block referred to the practice of PA using the short version of the International Physical Activity Questionnaire (IPAQ). IPAQ is used to obtain internationally comparable data on health-related PA for use with young and middle-aged adults (15-69 years) [16,17]. It contains 7 open-ended questions providing information on time spent in vigorous- and moderate- intensity PA, walking, and in sedentary activity during the previous 7 days.

\subsection{Anthropometric status assessment}

Height and weight were used to calculate BMI, waist and hip circumference to calculate WHR, and waist circumference and height were used to calculate WHtR.

\subsection{PA assessment}

From different domains of PA and sitting several variables were analyzed: the frequency and time spent per week in vigorous physical activities, the frequency and time spent per week in moderate physical activities, the frequency and time spent per week in walking, and the frequency and time spent per week in sitting.

The separate scores on walking, moderate-intensity and vigorous-intensity activity were calculated by multiplying the minutes spent in each activity by the number of days of the activity. The volume of each activity was computed by weighting each type of activity by its energy requirements defined in METs to yield a score in MET-minutes. METs are multiples of the resting metabolic rate and a MET-minute. According to the guidelines for data processing and analysis of the IPAQ MET-min per week for each of walking, moderate- and vigorous intensity activities were calculated as follows: walking $=(3.3 \times$ walking $\min \times$ walking days $)$; moderate activity $=(4.0 \times$ moderate activity min $\times$ moderate activity days $)$; vigorous activity $=(8.0 \times$ vigorous activity $\min \times$ vigorous activity days $)$. Sum of these activities gives total MET-minutes/week:

Total MET-minutes $/$ week = Walk (METs*min*days) + Mod (METs*min*days) + Vig (METs*min*days)

Total physical activity score was used for classification level of PA: high ( $\geq 3000$ MET-min /Week), moderate (600-2999 MET-min /Week) and low (<600 MET-min /Week) [18].

The WHO global recommendation on PA for health for adults (aged 18-64 years) is at least 150 minutes of moderateintensity activity per week, or at least 75 minutes of vigorous-intensity physical activity throughout the week or an equivalent combination of moderate-intensity and vigorous-intensity activity [10]. Vigorous and moderate physical 
activities for each subject measured were classified as meeting or not meeting WHO criteria for physical activity for health.

\subsection{Statistical analysis}

Statistical analyses were performed using the Statistical Package for Social Sciences software (IBM, version 23.0). Continuous data were presented as mean and standard deviation (SD) and compared using Student t-test. In the bivariate analysis, the association (using Pearson's chi-squared test) of anthropometric measures were estimated according to the average time spent at the weekly level in walking, moderate-intensity, vigorous-intensity activity, and sitting. Differences were considered statistically significant at $\mathrm{p}<0.05$.

\section{Results}

\subsection{General information of students participated in the study}

A sample included 56 students, of which 43 (76.79\%) were female and 13 (23.21\%) were male. A more detailed profile of the students' characteristics is presented in Table 3.

Table 3 General information of students participated in the study

\begin{tabular}{|c|c|c|c|c|}
\hline Variable & & Females & Males & $\mathbf{p}$ \\
\hline \multicolumn{2}{|c|}{ Number of students (\%) } & $43(76.79 \%)$ & $13(23.21 \%)$ & \\
\hline \multirow{7}{*}{$\begin{array}{l}\text { Anthropometric } \\
\text { measures }\end{array}$} & Weight $($ mean \pm SD) & $61.86 \pm 0.98 \mathrm{~kg}$ & $89.46 \pm 3.47 \mathrm{~kg}$ & $<0,0005$ \\
\hline & Height (mean \pm SD) & $168.97 \pm 0.81 \mathrm{~cm}$ & $183.08 \pm 1.60 \mathrm{~cm}$ & $<0,0005$ \\
\hline & $\mathrm{BMI}($ mean $\pm \mathrm{SD})$ & $21.76 \pm 0.36 \mathrm{~kg} / \mathrm{m}^{2}$ & $26.69 \pm 0.95 \mathrm{~kg} / \mathrm{m}^{2}$ & $<0,0005$ \\
\hline & $\mathrm{WC}(\mathrm{mean} \pm \mathrm{SD})$ & $70.95 \pm 1.20 \mathrm{~cm}$ & $90.77 \pm 4.13 \mathrm{~cm}$ & $<0,0005$ \\
\hline & WHtR (mean \pm SD) & $0.42 \pm 0.05$ & $0.50 \pm 0.08$ & $<0,0005$ \\
\hline & Hip circumference (mean \pm SD) & $93.80 \pm 1.22 \mathrm{~cm}$ & $96.62 \pm 3.99 \mathrm{~cm}$ & 0,368 \\
\hline & WHR (mean \pm SD) & $0.76 \pm 0.08$ & $0.94 \pm 0.07$ & $<0,0005$ \\
\hline \multirow{4}{*}{$\begin{array}{l}\text { Average time } \\
\text { spent at the } \\
\text { weekly level in }\end{array}$} & Vigorous PA & $73.84 \pm 13.83 \mathrm{~min}$ & $167.31 \pm 36.34 \mathrm{~min}$ & 0,029 \\
\hline & Moderate PA & $207.67 \pm 29.88 \mathrm{~min}$ & $186.92 \pm 37.08 \mathrm{~min}$ & 0,723 \\
\hline & Walking & $161.40 \pm 27.04 \mathrm{~min}$ & $185.77 \pm 61.24 \mathrm{~min}$ & 0,683 \\
\hline & Sitting & $297.21 \pm 20.75 \mathrm{~min}$ & $420.00 \pm 58.93 \mathrm{~min}$ & 0,016 \\
\hline \multicolumn{2}{|c|}{ MET-minutes per week } & $1984.52 \pm 1290.27$ & $2699.19 \pm 1718.04$ & $<0,0005$ \\
\hline
\end{tabular}

\subsection{Anthropometric measures and health risk}

It is showed by Table 4 that the majority of the students (76.78\%) were of normal weight according to BMI. The BMI > 24.9 was found at $11(19.65 \%)$. Based on the WC, metabolic risk was determined in $10(17.86 \%)$ subjects. Based on the WHtR, a higher health risk was found in 8 (14.29\%) subjects. Based on the WHR, a higher health risk was found in 11 $(19.64 \%)$ subjects. 
Table 4 Anthropometric indicators of health risk

\begin{tabular}{|c|c|c|c|c|}
\hline Indicator & Classification / Cut-off (health risk) & $\begin{array}{l}\text { Females } \\
\text { Number (\%) }\end{array}$ & $\begin{array}{l}\text { Males } \\
\text { Number (\%) }\end{array}$ & $\begin{array}{l}\text { Total } \\
\text { Number (\%) }\end{array}$ \\
\hline \multirow{4}{*}{ BMI } & Underweight $\leq 18.5$ (Low) & $2(4.65)$ & - & $2(3.57)$ \\
\hline & Normal 18.5-24.9 (Average) & $38(88.37)$ & $5(38.46)$ & $43(76.78)$ \\
\hline & Overweight 25-29.9 (Increased) & $3(6.98)$ & $5(38.46)$ & $8(14.29)$ \\
\hline & Obese class I 30-34.9 (Moderate) & - & $3(23.08)$ & $3(5.36)$ \\
\hline \multirow[t]{3}{*}{ WC } & $<94$ for males and <80 females (Average) & $38(88.37)$ & $8(61.54)$ & $46(82.14)$ \\
\hline & $\begin{array}{l}\geq 94<102 \text { for males and } \geq 80<88 \text { for females } \\
\text { (Increased) }\end{array}$ & $4(9.30)$ & $3(23.08)$ & $7(12.50)$ \\
\hline & $\begin{array}{l}\geq 102 \text { for males and } \geq 88 \text { for females } \\
\text { (Substantially increased) }\end{array}$ & $1(2.33)$ & $2(15.38)$ & $3(5.36)$ \\
\hline \multirow[t]{2}{*}{ WHtR } & $<0.54$ for males and $<0.49$ for females (Average) & $38(88.37)$ & $10(76.92)$ & $48(85.71)$ \\
\hline & $\begin{array}{l}\geq 0.54 \text { for males and } \geq 0.49 \text { for females } \\
\text { (Increased) }\end{array}$ & $5(11.63)$ & $3(23.08)$ & $8(14.29)$ \\
\hline \multirow[t]{2}{*}{ WHR } & $<0.95$ for males and $<0.85$ for females (Average) & $38(88.37)$ & $7(53.85)$ & $45(80.36)$ \\
\hline & $\begin{array}{l}\geq 0.95 \text { for males and } \geq 0.85 \text { for females } \\
\text { (Increased) }\end{array}$ & $5(11.63)$ & $6(46.15)$ & $11(19.64)$ \\
\hline
\end{tabular}

\subsection{PA assessment}

Pattern of PA was determined on the basis of PA scores and levels were calculated

Table 5 Pattern of PA

\begin{tabular}{|l|l|l|l|l|}
\hline \multicolumn{2}{|l|}{ Pattern of PA } & Females Number (\%) & Males Number (\%) & Total Number (\%) \\
\hline \multirow{4}{*}{ PA level } & Low (MET<600) & $4(9.30)$ & $2(15.39)$ & $6(10.71)$ \\
\cline { 2 - 5 } & Moderate (600-3000) & $31(72.09)$ & $6(46,15)$ & $37(66.08)$ \\
\cline { 2 - 5 } & High (MET $\geq 3000)$ & $8(18.61)$ & $5(38.46)$ & $13(23.21)$ \\
\hline \multirow{4}{*}{ Vigorous PA } & $<10 \mathrm{~min} /$ week & $17(39.54)$ & $3(23.08)$ & $20(35.71)$ \\
\cline { 2 - 5 } & $10-75 \mathrm{~min} /$ week & $9(20.92)$ & $1(7.69)$ & $10(17.86)$ \\
\cline { 2 - 5 } & $\geq 75 \mathrm{~min} /$ week & $17(39.54)$ & $9(69.23)$ & $26(46.43)$ \\
\hline \multirow{5}{*}{ Moderate PA } & $<10 \mathrm{~min} /$ week & $1(2.32)$ & $2(15.38)$ & $3(5.36)$ \\
\cline { 2 - 5 } & $10-150 \mathrm{~min} /$ week & $17(39.54)$ & $3(23.08)$ & $20(35.71)$ \\
\cline { 2 - 5 } & $\geq 150 \mathrm{~min} /$ week & $25(58.14)$ & $8(61.54)$ & $33(58.93)$ \\
\hline \multirow{3}{*}{ Walking } & $<60 \mathrm{~min} /$ week & $13(30.23)$ & $2(15.39)$ & $15(26.78$ \\
\cline { 2 - 5 } & $60-150$ & $14(32.56)$ & $5(38.46)$ & $19(33.93)$ \\
\cline { 2 - 5 } & $\geq 150 \mathrm{~min} /$ week & $16(37.21)$ & $6(46.15)$ & $22(39.29)$ \\
\hline
\end{tabular}

According to the IPAQ scoring system, 10.71\% of students had low level of PA, 66.08 were moderate and 23.21 were high physically active. 
World Journal of Advanced Research and Reviews, 2020, 08(01), 093-101

In sample $46.43 \%$ performed vigorous intensity activities that meet with WHO criteria, 58.93 performed moderate intensity activities that meet with WHO criteria, and $39.29 \%$ performed walking activities that meet with WHO criteria.

\subsection{Correlation between anthropometric indicators of health risk and PA pattern}

Correlations between the different tested variables are presented in Table 5.

Table 5 Pearson correlation between anthropometric indicators of health risk and PA pattern.

\begin{tabular}{|l|l|l|l|l|}
\hline \multirow{2}{*}{ Indicator } & \multicolumn{4}{l}{ The average time spent during 7 days in } \\
\cline { 2 - 5 } & Vigorous PA & Moderate PA & Walking & Sitting \\
\hline BMI & $\mathrm{P}=0.003(0.384)$ & $\mathrm{P}=0.348(0.126)$ & $\mathrm{P}=0.602(-0.071)$ & $\mathrm{P}=0.403(0.114)$ \\
\hline WC & $\mathrm{P}=0.005(0.368)$ & $\mathrm{P}=0.914(0.015)$ & $\mathrm{P}=0.563(0.079)$ & $\mathrm{P}=0.078(0.237)$ \\
\hline WHtR & $\mathrm{P}=0.023(0.303)$ & $\mathrm{P}=0.914(-0.015)$ & $\mathrm{P}=0.836(0.028)$ & $\mathrm{P}=0.196(0.175)$ \\
\hline WHR & $\mathrm{P}=0.003(0.387)$ & $\mathrm{P}=0.384(-0.119)$ & $\mathrm{P}=0.930(-0.012)$ & $\mathrm{P}=0.457(0.101)$ \\
\hline
\end{tabular}

There were positive, statistically significant difference between indicators of health status and the average time spent during 7 days in vigorous PA.

\section{Discussion}

The purpose of this study was to investigate the relationships of physical activity domains in everyday life and sedentary behavior with the anthropometrical parameters among students of sixth year of the Faculty of Medicine of Sarajevo University. A cross-sectional study was conducted during May 2020 and included 56 students. Anthropometric measures (height, weight, waist and hip circumference) were used to calculate BMI, WHtR and WHR, the anthropometric markers related to risk of metabolic complication. The majority of the students (76.78\%) were of normal weight according to BMI. The BMI > 24.9 was found at $11(19.65 \%)$. Based on the waist circumference, metabolic risk was determined in 10 (17.86\%) subjects. Based on the WHtR, a health risk was found in 8 (14.29\%) subjects. Based on the WHR, a higher health risk was found in $11(19.64 \%)$ subjects.

Overweight and obesity prevalence has been reported in all age groups worldwide [2], including college students as well [19]. In terms of the BMI for students from the University of Banja Luka there were $22.40 \%$ overweight students, while $2.40 \%$ of them were obese [20]. Applying BMI, $21.9 \%$ and $20.6 \%$ of students were classified as overweight and obese, respectively during a cross-sectional study at the Colleges of Medicine and Nursing at the King Saud binAbdulaziz University for Health Sciences, National Guard Health Affairs, in Riyadh, Saudi Arabia. Abdominal obesity was prevalent in $26.9 \%$ and $42.2 \%$ of students based on WC and WHtR, respectively [21].

Male students compared to female declared more time spent in vigorous PA ( $t$ test: $p=0.029 ; \mathrm{p}<0.05)$. The same finding has been reported in study carried out in the health colleges of King Khalid University [22].

According to the IPAQ scoring system, in present study $10.71 \%$ of students had low level of PA, 66.08 were moderate and 23.21 were high physically active. Some studies showed a high prevalence of physical inactivity among university students [22,23]. In our sample 46.43\%, 58.93, and 39.29\% of the students performed vigorous intensity activities, moderate intensity activities, and walking activities that meet with WHO criteria. Miller reported that nearly half and nearly three-fifth of university students were vigorously and moderately physically active [24]. The high prevalence of inactivity among university students in some study can be explained by environmental factors [22].

There was statistically significant relationship found between anthropometric indicators of health status and the average time spent during 7 days in vigorous PA. There are various research results of effect of PA on BMI. Cameron emphasized strong positive associations between obesity and lower physical activity [25]. Aziz reported that some students were obese and still have high physical activity level while some are normal in BMI and having low physical activity level [26].

Increased the prevalence of obesity observed in USA had the greatest magnitude of in the following groups: 18- to 29year-olds (7.1\% to $12.1 \%)$, and those with some college education (10.6\% to $17.8 \%)$ [27]. 


\section{Conclusion}

This study has some limitations. The cross-sectional design does not allow to follow changes in anthropometric indicators depending on undertake different intensity of physical activity. In this study, the reverse causality could explain observed associations between PA and the outcomes analyzed. Some individuals in this study may have started the practice of PA for having found themselves obese. Nevertheless the present study highlights an important issue of the health of college students: the anthropometric indicators of abdominal obesity can be increase despite satisfied level of physical activity. It is important to raise awareness about the possible discrepancy between energy consumption and energy intake. When physical activity intensifies, there is often an increase in appetite and increased caloric intake. If the caloric intake does not correspond to energy consumption, there may be an increase in body weight. It is suggested to keep a diary with data on the type and number of meals, and the type and amount of food. Understanding strategies to adopt healthy life style would make health college students competent to promote and disseminate healthy lifestyle to the public.

\section{Supplementary file}

\subsection{Appendix IPAQ SF (17)}

1. During the last 7 days, on how many days did you do vigorous physical activities like heavy lifting, digging, aerobics, or fast bicycling?

days per week

$\square$ No vigorous physical activities $\rightarrow$ Skip to question 3

2. How much time did you usually spend doing vigorous physical activities on one of those days? hours per day

minutes per day

3. During the last 7 days, on how many days did you do moderate physical activities like carrying light loads, bicycling at a regular pace, or doubles tennis?

Do not include walking.

days per week

$\square$ No moderate physical activities $\rightarrow$ Skip to question 5

4. How much time did you usually spend doing moderate physical activities on one of those days? hours per day minutes per day

5. During the last 7 days, on how many days did you walk for at least 10 minutes at a time? days per week

$\square$ No walking $\rightarrow$ Skip to question 7

6. How much time did you usually spend walking on one of those days? hours per day minutes per day

7. During the last 7 days, how much time did you spend sitting? hours per day minutes per day

\section{Compliance with ethical standards}

\section{Acknowledgments}

The authors would like to thank the participants who involved in this study.

\section{Disclosure of conflict of interest}

The authors declare that they have no competing interests. 


\section{Statement of informed consent}

Informed consent was obtained from all individual participants included in this study.

\section{References}

[1] WHO/FAO. Diet, nutrition and the prevention of chronic diseases. Report of Joint WHO/FAO Expert Consultation. Geneva, World Health Organization/Food and Agriculture Organization (WHO/FAO). 2003.

[2] WHO. Obesity and overweight Fact sheet" WHO. 2020.

[3] WHO/Regional Office for Europe. Diet, Physical Activity and Obesity, Bosnia and Herzegovina. 2013.

[4] WHO. Waist circumference and waist-hip ratio: report of a WHO expert consultation. Geneva, Switzerland. 2008.

[5] WHO. Obesity: preventing and managing the global epidemic: report of a WHO consultation. Consultation on Obesity. Geneva, Switzerland. 2008.

[6] Schneider HJ, Friedrich N, Klotsche J, Pieper L, Nauck M, John U, Dörr M, Felix S, Lehnert H, Pittrow D, Silber S, Völzke H, Stalla GK, Wallaschofski H, Wittchen HU. The predictive value of different measures of obesity for incident cardiovascular events and mortality. J Clin Endocrinol Metab. 2010; 95: 1777-1785.

[7] Caspersen BCJ, Powell KE, Christenson GM. Physical activity, exercise, and physical fitness: Definitions and distinctions for health related research. Public Health Reports. 1985; 100(2): 126-30.

[8] U.S. Department of Health and Human Services. Physical Activity Guideline for Americans, 2nd edition. 2018.

[9] World Health Organization. Global recommendations on physical activity for health. Geneva, Switzerland. 2010.

[10] WHO. Global action plan on physical activity 2018-2030: more active people for a healthier world. Geneva, Switzerland. 2018.

[11] Tremblay MS, Aubert S, Barnes JD, Saunders TJ, Carson V, Latimer-Cheung AE, Chastin SFM., Altenburg TM, Chinapaw MJM, Participants STCP. Sedentary behaviour research network (SBRN) - terminology consensus project process and outcome. Int J Behav Nutr Phys Act. 2017; 14(1): 75.

[12] Booth FW, Roberts CK, Laye MJ. Lack of exercise is a major cause of chronic diseases Compr Physiol. 2012; 2(2): 1143-1211.

[13] Gordon-Larsen P, Adair LS, Nelson MC, Popkin BM. Five-year obesity incidence in the transition period between adolescence and adulthood: The national longitudinal study of adolescent health. Am J Clin Nutr. 2004; 80(3): 569-575.

[14] Gordon-Larsen P, The NS, Adair LS. Longitudinal trends in obesity in the United States from adolescence to the third decade of life. Obesity (Silver Spring). 2010; 18(9): 1801-1804.

[15] World Medical Association. Declaration of Helsinki: Ethical Principles for Medical Research Involving Human Subjects. JAMA. 2013; 310(20): 2191-4.

[16] International Physical Activity Questionnaires [Internet].

[17] International Physical Activity Questionnaire - Short Form [Internet].

[18] IPAQ Research Committee. Guidelines for data processing and analysis of the international physical activity question- naire (IPAQ)—short and long forms. Stockholm: Karolinska Institutet. 2005.

[19] Saghafi-Asl M, Aliasgharzadeh S, Asghari-Jafarabadi M. Factors influencing weight management behavior among college students: An application of the Health Belief Model. Plose One. 2020; 15(2): e0228058.

[20] Raseta N, Duric S, Zeljekovic N, Simovic S, Vujnic M. Interrelations between body mass index, percentage of body fat, and waist-to-hip ratio among different groups of students at the university of Banja Luka. Facta Universitatis. Physical Education and Sport. 2016; 14(3): 331-345.

[21] Schneider HJ, Friedrich N, Klotsche J, Pieper L, Nauck M, John ., Dorr M, Felix S, Lehnert H, Pittrow D, Silber S, Volzke H, Stalla GK, Wallaschofski H, Wittchen HU. The predictive value of different measures of obesity for incident cardiovascular events and mortality. J Clin Endocrinol Metab. 2010; 95: 1777-1785. 
[22] Awadalla NJ, Aboelyazed AE, Hassanein MA, Khalil SN, Aftab R, Gaballa II, Mahfouz AA. Assessment of physical inactivity and perceived barriers to physical activity among health college students, south-western Saudi Arabia. EMHJ. 2014; 20(10): 596-604.

[23] Al-Isa AN, Campbell J, Desapriya E, Wijesinghe N. Social and health factors associated with physical activity among Kuwaiti college students. J Obes. 2011; Article ID 512363.

[24] Miller K, Staten RR, Rayens MK, Noland M. Levels and characteristics of physical activity among a college student cohort. American Journal of Health Education. 2005; 36(4): 215-220.

[25] Cameron A, Welborn T, Zimmet P, Dunstan D, Owen N, Salmon J, Dalton M, Jolley D, Shaw J. Overweight and obesity in Australia: the 1999-2000 Australian Diabetes, Obesity and Lifestyle Study (AusDiab). Med J Aust. 2003; 178: 427-432.

[26] Aziz K, Afridi A, Arif A, Shahid G, Fahim MF, Khan R. Association of physical activity levels and BMI among doctor of physical therapy students of a private college from Karachi. JBUMDC. 2019; 9(4): 281-285.

[27] Mokdad AH, Serdula MK, Dietz WH, Bowman BA, Marks JS, Koplan JP. The Spread of the Obesity Epidemic in the Unites States, 1991-1998. JAMA. 1999; 282(16): 1519-1522. 